\title{
Carbonate Coatings as Protective Barriers for Pipe Borne Water Transport Material
}

\section{Lasisi Ejibunu Umoru, Abimbola Oladipo, and Oladeji Oluremi Ige*}

\author{
Department of Materials Science and Engineering, Obafemi Awolowo University, Ile- \\ Ife,Nigeria \\ *Corresponding Author: ige4usa@yahoo.com
}

\begin{abstract}
This paper presents the report of corrosion prevention study carried out on plain carbon steel lined with calcite, magnesium carbonate and dolomite as coats. Eight samples each of the steel were dipped into solutions of $\mathrm{CaCO}_{3}, \mathrm{CaCO}_{3}$ and $\mathrm{MgCO}_{3}$, and $\mathrm{MgCO}_{3}$. Pipe borne water obtained from Obafemi Awolowo University, Ile-Ife water works was used as the environment. The corroded sample surfaces were subject to microstructural characterization using optical microscopy technique. The results obtained showed that the steel exhibited minimum corrosion rate of less than $0.5 \mathrm{~mm} / \mathrm{yr}$ in dolomite, followed by $\mathrm{MgCO}_{3}$ and then by $\mathrm{CaCO}_{3}$ with corrosion rate far above $0.5 \mathrm{~mm} / \mathrm{yr}$ bench mark. The unlined (control) samples have maximum corrosion rate of $0.8 \mathrm{~mm} / \mathrm{yr}$. the microstructures revealed widespread localized attacks and to a uniform corrosion. The dolomite lined samples are recommended for corrosion prevention of plain carbon steel in pipe borne water.
\end{abstract}

Keywords: Plain carbon steel, Calcite, $\mathrm{MgCO}_{3}$, Dolomite and Microstructure

\section{INTRODUCTION}

Carbon steel is regarded as the most widely used engineering material because it accounts for approximately $85 \%$ of the annual steel production worldwide. It also represent the largest single class of alloys in use, both in terms of tonnage and total cost, it is easy to understand why its corrosion is a problem of enormous practical importance. Hence there is a need to provide protective systems for iron and steel. Carbon steel have numerous applications and one of the most versatile is its usage as pipes and vessels and these are often employed to transport water or 
are submerged in water to some extent during service [1]. Generally it is believed that corrosion is a major problem associated with the use of this material in aqueous environment therefore there is a need to control and prevent this degradation. Coatings have been established as one of the most efficient methods of reducing corrosion, although there are several means of coating but in this study, the effects of calcite and dolomite on carbon steel are to be investigated.

Calcite is one of the most common minerals and it comprises of about $4 \mathrm{wt} \%$ of the earth's crust and it is formed in many different geological environments. While dolomite is a common sedimentary rock-forming mineral that can be found in massive beds several hundred feet thick and they are also found in metamorphic marbles, hydrothermal veins and replacement deposits. Dolomite is hard to distinguish from its second cousin calcite but the latter is far more common and effervesces easily when acid is applied to it. However, this is not the case with dolomite which only weakly bubbles with acid only when the acid is warm or the dolomite is powdered. They also differ based on their chemical composition, in dolomite there is presence of magnesium ions [2-3].

Artificial calcite lining represents a novel technique for the rehabilitation of water mains. Calcite linings similar to the commonly used cement-mortar linings, are of porous nature and as such are able to accumulate corrosion products inside their linings thus serving as a means of mitigating internal corrosion in pipe walls [4]. The quality of calcite films artificially deposited by an electrochemical reaction was observed to deposit the best, least permeable films from hard water $[5]$.

The role of $\mathrm{CaCO}_{3}$ in corrosion and its control in water distribution systems evokes widespread interest from several points of view. The iron oxide layer formed on a pipe surface in contact with water having even a minor amount of $\mathrm{Ca}^{2+}$ and $\mathrm{HCO}^{-3}$ ions contains some $\mathrm{CaCO}_{3}$. It is widely believed that $\mathrm{CaCO}_{3}$ formation represents a cathodic inhibition mechanism that serves to protect the pipe surface from corrosion [6-7].

The effect of $\mathrm{MgCO}_{3}$ also follows the same mechanism. However, this study is undertaken to establish the effect of dolomite on the corrosion prevention of plain carbon steel.

\section{EXPERIMENTAL}

The plain carbon steel used was of commercial standards and its chemical composition is as presented in Table 1. The corrosion environment used in the research was pipe borne water obtained from Obafemi Awolowo University, Ile-Ife water works. $1.42 \mathrm{~cm}$ diameter cylindrical specimens of length $1.09 \mathrm{~cm}$ were cut and thirty-two (32) specimens were produced. The test coupons had their surfaces ground with hand file and pickled by dipping each specimen in 5\% $\mathrm{HCl}$ for half an hour at room temperature. 
Table1: $\quad$ The Chemical Composition of Bulk Steel Sample

\begin{tabular}{|l|l|l|l|l|l|l|l|l|l|}
\hline Elements & $\mathrm{C}$ & $\mathrm{S}$ & $\mathrm{P}$ & $\mathrm{Mn}$ & $\mathrm{Ni}$ & $\mathrm{Cr}$ & $\mathrm{Mo}$ & $\mathrm{V}$ & $\mathrm{Cu}$ \\
\hline Composition, \%wt. & 0.2022 & 0.0275 & 0.0275 & 0.5966 & 0.0915 & 0.0863 & 0.0145 & 0.0028 & 0.2058 \\
\hline Elements & $\mathrm{W}$ & $\mathrm{As}$ & $\mathrm{Sn}$ & $\mathrm{Co}$ & $\mathrm{Al}$ & $\mathrm{Pb}$ & $\mathrm{Ca}$ & $\mathrm{Zn}$ & $\mathrm{Si}$ \\
\hline Composition, \%wt. & 0.0012 & 0.0015 & 0.0203 & 0.0071 & 0.0017 & 0.0015 & 0.0002 & 0.0038 & 0.1823 \\
\hline
\end{tabular}

All the specimens were washed, degreased in acetone and then dried prior to taking initial weight measurement on a Toledo Mettler balance to $0.001 \mathrm{~g}$ accuracy. Afterward the coupons were stored in desiccators. Three different lining solutions were used. $\mathrm{MgCO}_{3}$ lining solution was prepared by measuring $19.374 \mathrm{~g}$ of $\mathrm{MgCO}_{3}$ powder into supersaturated solution. The calcite lining solution was prepared by making $23.0643 \mathrm{~g}$ of $\mathrm{CaCO}_{3}$ powder into a supersaturated solution. Each of $\mathrm{CaCO}_{3}(23.0643 \mathrm{~g})$ and $\mathrm{MgCO}_{3}(19.374 \mathrm{~g})$ were combined and made into a supersaturated solution which served as the dolomite lining solution.

Eight specimens each were immersed in the three lining solutions for a period of twenty four (24) hours to allow for precipitation on the sample surface. Thereafter, the samples were dried. Another eight of the pickled samples were dried but not coated/lined were used as control experiment. Immediately afterwards, the coupons were immersed completely in the pipe borne water. The experiment was put under close monitoring for a period of 49 days and one specimen was removed per week. On the completion of each exposure test, the coupons were cleaned with wire brush, rinsed under tap and dried prior to second weighing of samples to determine weight losses due to corrosion.

Microstructural examinations of the corroded sample surfaces were carried out with the aid of ACCUSCOPE OPTICAL MICROSCOPE. The corrosion rate $(\mathrm{R})$ was calculated using the expression:

$$
R=\frac{87.6 W}{D A T} \mathrm{D}
$$

where $\mathrm{D}$ is the density of specimen $\left(\mathrm{g} / \mathrm{cm}^{3}\right), \mathrm{A}$ is the total surface area $\left(\mathrm{cm}^{2}\right), \mathrm{T}$ is the time of exposure (hours) and $\mathrm{W}$ is the weight loss (mg).

\section{RESULTS}

Figures 1-3 show the effects of the calcite, magnesium carbonate and dolomite linings respectively on the corrosion rates of the plain carbon steel. The unlined steel exhibited higher corrosion rates than the other ones. Comparing the three figures, it is clear that dolomite conferred the greatest corrosion resistance on the lined steel. This is corroborated by the relative corrosion rates of lined and unlined steel as contained in the composite representation of the overall results of the study. 
Dolomite $\left(\mathrm{MgCO}_{3} \cdot \mathrm{CaCO}_{3}\right)$ offered the best corrosion protection (least corrosion rate) when compared to the other lining materials - calcite $\left(\mathrm{CaCO}_{3}\right)$ and $\mathrm{MgCO}_{3}$. Samples coated with dolomite initially had a sharp decrease in their corrosion rate from above $2.5 \mathrm{~mm} / \mathrm{yr}$ to below 0.5 $\mathrm{mm} / \mathrm{yr}$ within the first 192 hours of exposure time and the corrosion rate remained stable below this value for the remaining time of exposure. In the case of $\mathrm{MgCO}_{3}$, the corrosion rate remained on the high side of the $0.5 \mathrm{~mm} / \mathrm{yr}$ mark all through the entire time of exposure. While for calcite lined samples, the corrosion rates fluctuated above $0.5 \mathrm{~mm} / \mathrm{yr}$ for the first 911 hours; dropped below this mark at the $912^{\text {th }}$ hours and returned above the mark after this time. The unlined samples (control) shows the highest degree of corrosion rate which stood at about $0.8 \mathrm{~mm} / \mathrm{yr}$. The composite results of the samples were as presented in Fig. 4. This figure gives the clear representation of the performance of the coatings as barrier for corrosion protection.

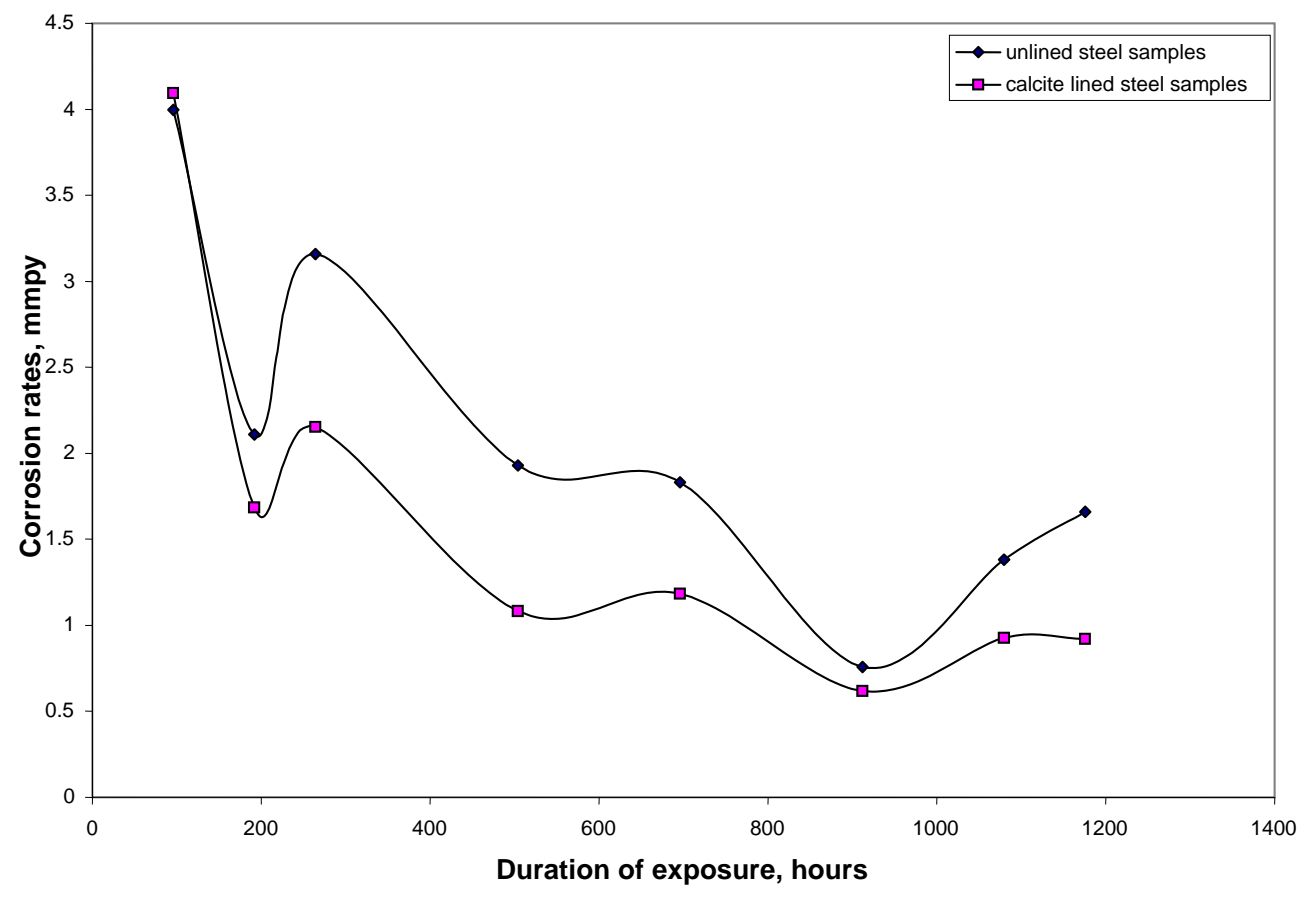

Fig.1: Graph showing the effect of calcite lining on the corrosion resistance of a plain carbon steel. 


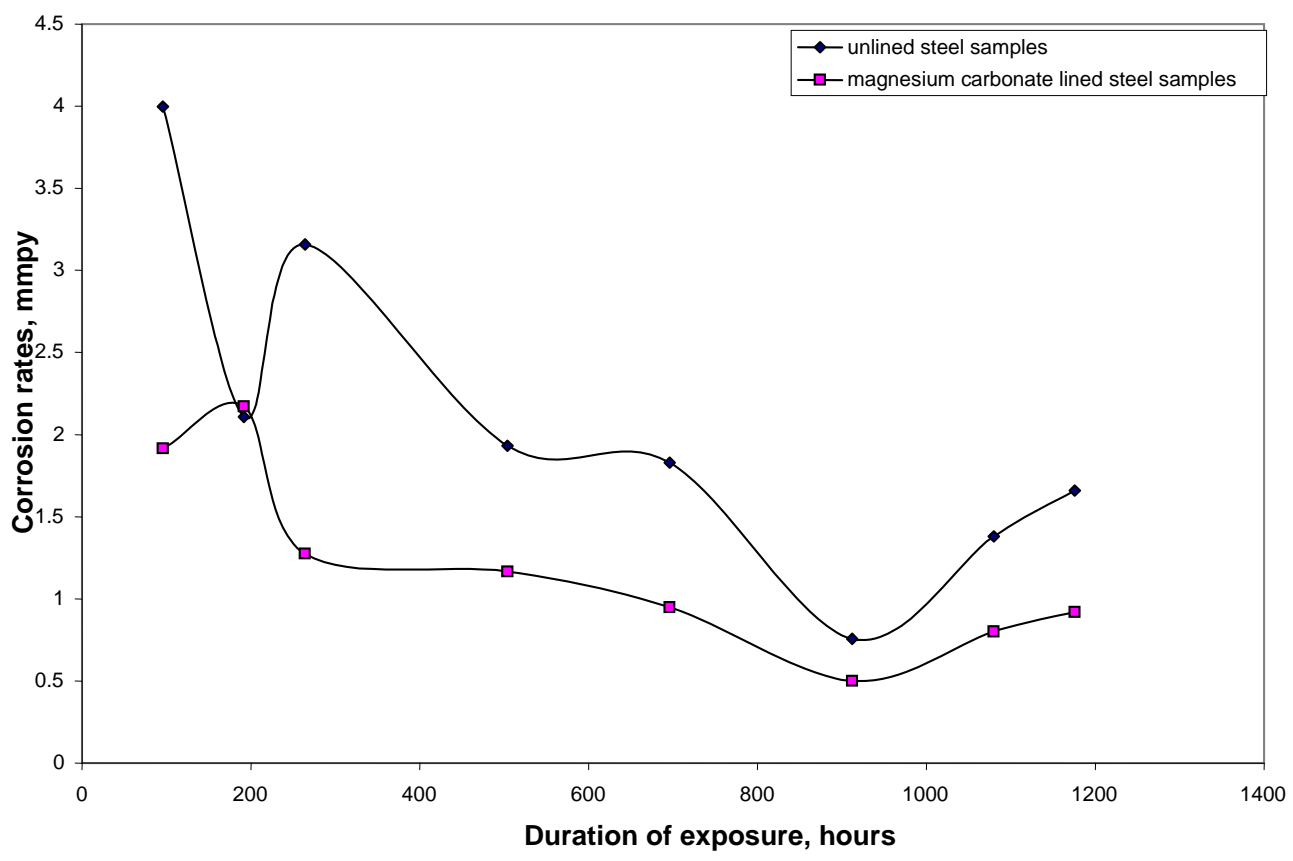

Fig.2 Graph showing the effect of magnesium carbonate lining on the corrosion resistance of a plain carbon steel.

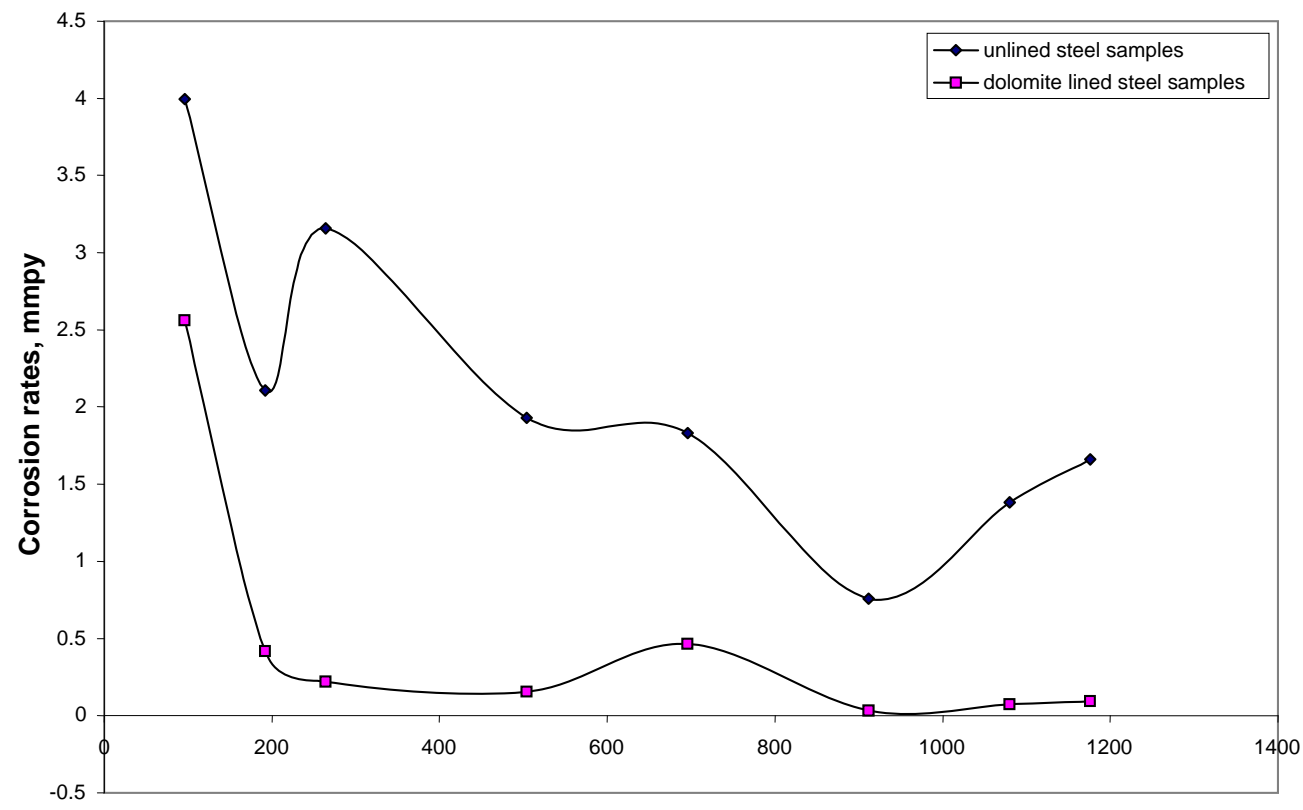

Duration of exposure, hours

Fig.3 Graph showing the effect of dolomite lining on the corrosion resistance of a plain carbon steel. 


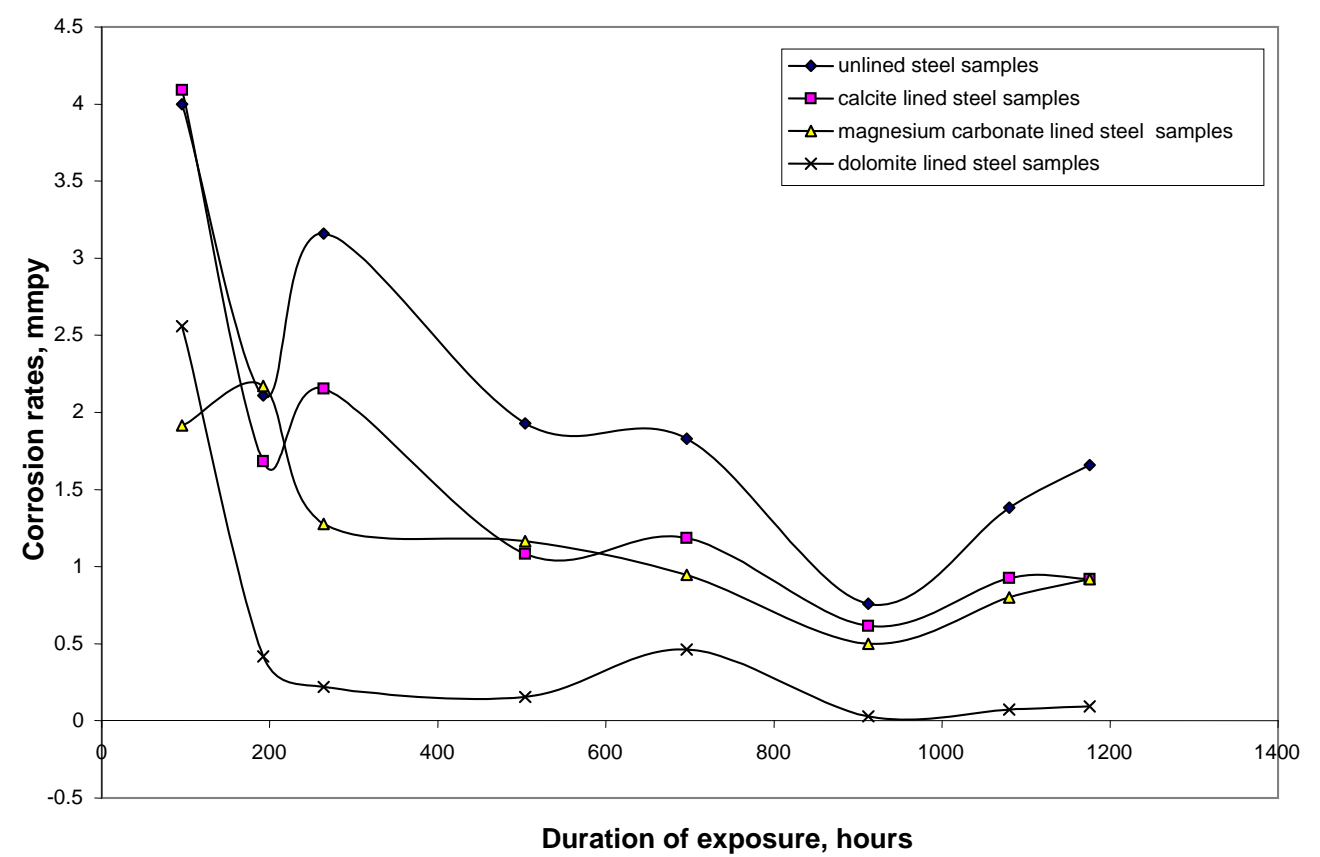

Fig.4 Graph showing the effect of different linings on the corrosion resistance of a plain carbon steel.

The micrographs will be evaluated based on the presence of the severity of the dark spots (cavities) and the presence of corrosion product and these determines the level of corrosion degradation encounter by the mild steel. Plate 1 shows the micrograph of unlined samples exposed after 21 days, it is characterized with severe localized corrosion attacks and the attacks are widespread. This implies that the samples suffer serious localized attack and coupled with the fact that there is no or little corrosion product on them. Corrosion products on the surface of a material are known to reduce the rate at which $\mathrm{n}$ environment can attack the material.

Plate 2 shows the micrograph of calcite lined sample exposed after 21 days. The corrosion attack were severe and highly localized while the corrosion product is scanty. The attack occurred along the grain boundaries with characteristic of deep pit which may be as a result of high energy associated with the region or it may be attributed to dissimilar corrosion. The microstructure of dolomite lined samples exposed after 21 days is as shown in Plate 3 and it revealed almost uniform corrosion product and localized attack. The corrosion product is also widespread but the attack is not served and the size of the pit is small. Plate 4 illustrates the corroded surfaces of $\mathrm{MgCO}_{3}$ lined sample after 21 days exposure in the pipe borne water. The cavities as found on the surface are smaller in size but are more widespread. 


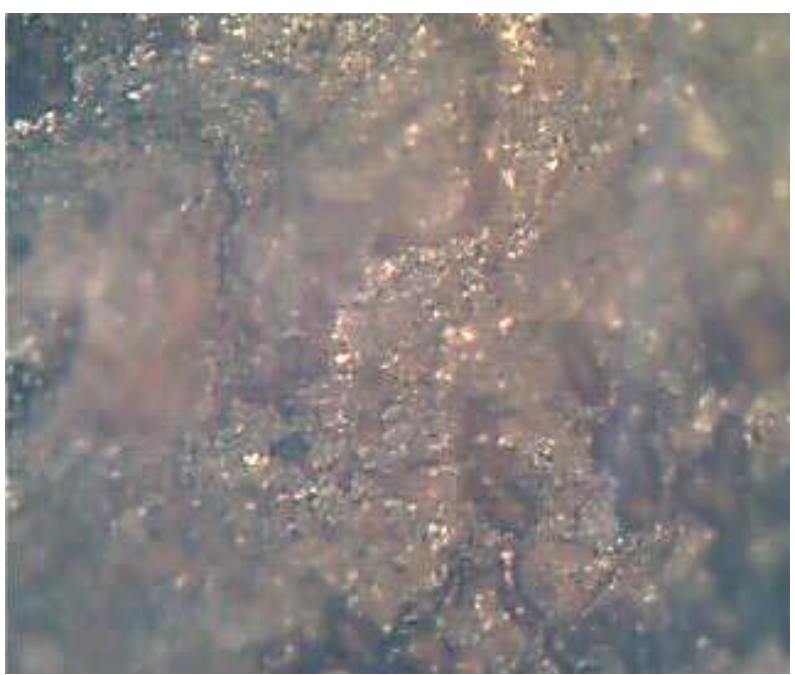

Plate1: Micrograph of unlined sample after 21 days of exposure. 100X

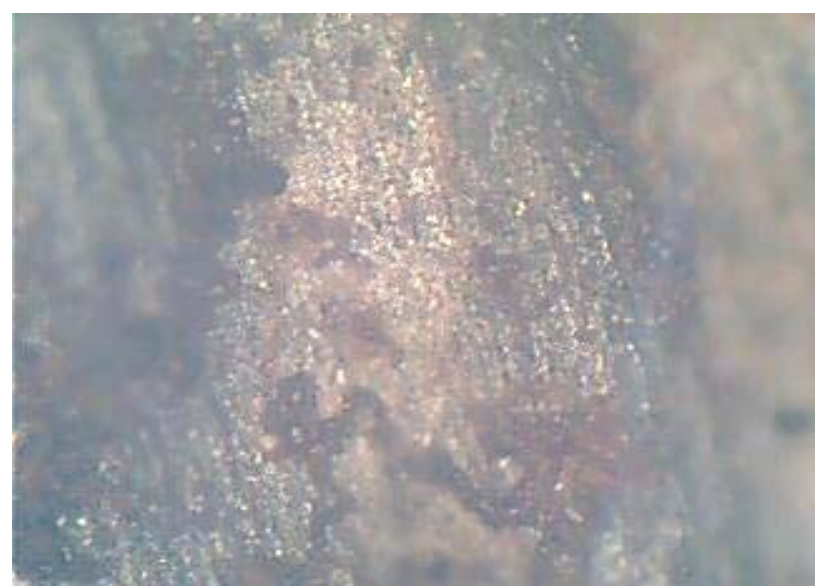

Plate 2: Micrograph of calcite lined sample after 21 days of exposure. 100X

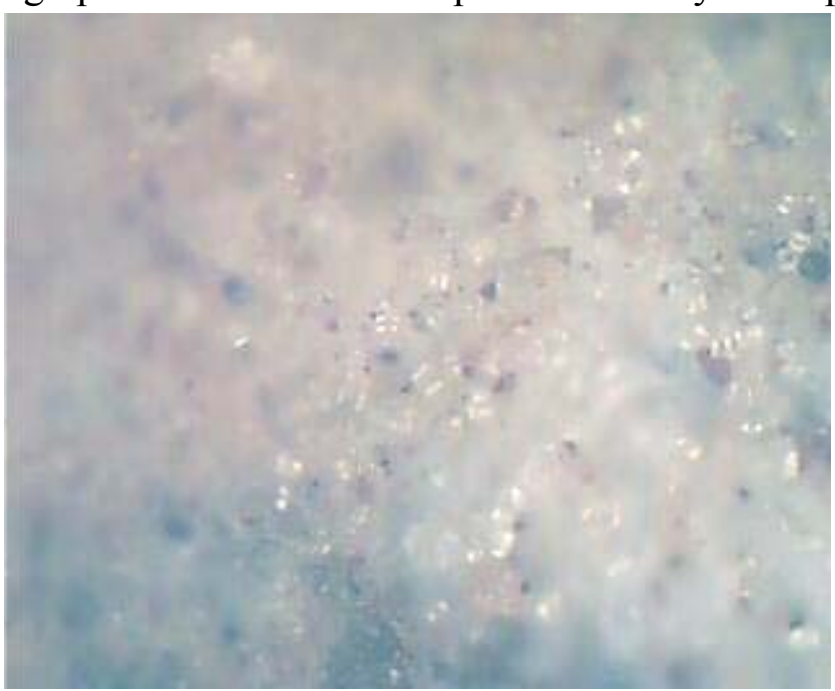

Plate 3: Micrograph of dolomite lined sample after 21 days of exposure. 100X 


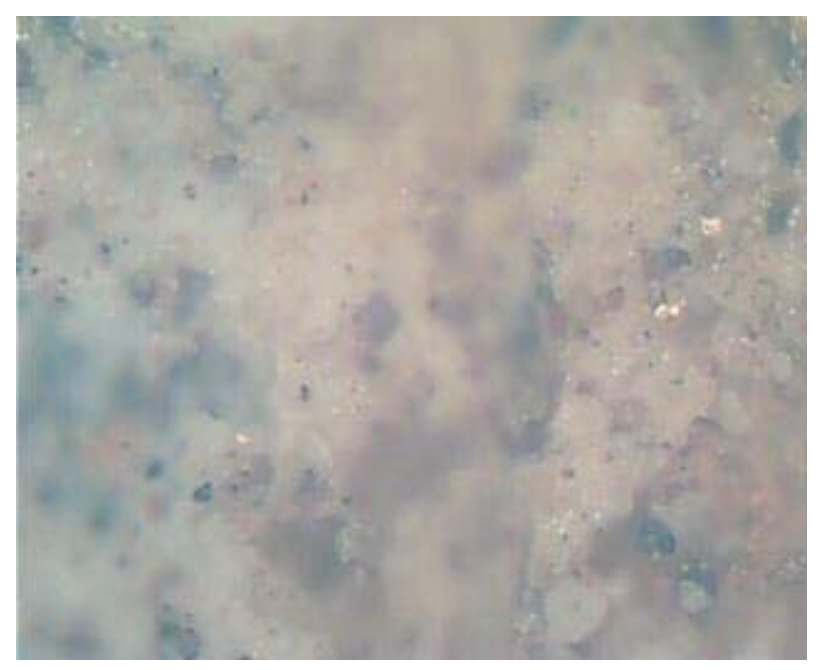

Plate 4: Micrograph of $\mathrm{MgCO}_{3}$ lined sample after 21 days of exposure. 100X

\section{DISCUSSION OF RESULTS}

The microstructure of natural scale layers formed in potable water supply mains having moderate to high hardness showed that the scale composed mostly of iron compounds - goethite $[\alpha-$ $\mathrm{FeO}(\mathrm{OH})]$, siderite $\left(\mathrm{FeCO}_{3}\right)$ and magnetite $\left(\mathrm{Fe}_{3} \mathrm{O}_{4}\right)$ - mixed with calcite $\left(\mathrm{CaCO}_{3}\right)$. The calcium rich scale tended to be denser and more electrically resistant; that is it has a better corrosion protection capability. Scales poor in calcite but rich in siderite still has a fairly high resistance. Scales poor in carbonates of $\mathrm{Fe}$ and $\mathrm{Ca}$ but rich in magnetite showed low resistance [8]. This can also be suggested to be the case of dolomite, the $\mathrm{Ca}$ and $\mathrm{Mg}$ - rich scales are denser and thus have more electrical resistance which result in better corrosion protection capability as seen when compared to calcite and $\mathrm{MgCO}_{3}$ linings.

Micrographically, it was observed that samples lined with $\mathrm{CaCO}_{3}$ and $\mathrm{MgCO}_{3}$ resulted in the formation of an oxide film on the metal. A double film was formed with dolomite lining. The thicker lining as expected provided better corrosion protection by providing for a greater probability of pore blockage by the corrosion products. Bulk density of the lining which represents the degree of porosity of the lining has a profound effect on the corrosion current. It was seen that increase of bulk lining density reduced the corrosion rate [4].

It has been established that uniform corrosion is preferred to localize attack due to the fact that they are less insidious [9]. This probably accounted for the low corrosion rate observed for samples lined with dolomite because they exhibits uniform corrosion unlike unlined samples which is characterized by localized attack and as such they do have low corrosion resistance. While the corrosion rate for calcite is more than that of $\mathrm{MgCO}_{3}$ because it suffers more localized attack. Generally the severities of the localized attacks were observed to follow this trend; unlined sample, calcite, $\mathrm{MgCO}_{3}$, and dolomite. Similarly the corrosion products are seen to be increasing in the same order and with spread is uniform. Corrosion protection of calcite lining 
depends on two mechanisms: promotion of a protective oxide film on the metal and accumulation of corrosion products retarding oxygen diffusion [4]. However in a similar but more effective manner, dolomite showed better corrosion mitigation due to double protection offered by its constituents. This was used to explain the lower corrosion rate seen in the dolomite lining which contain double hard water constituents as compared with that of calcite and $\mathrm{MgCO}_{3}$ linings [5].

The failure of linings can occur when the corrosion products within the dolomite, $\mathrm{MgCO}_{3}$ and calcite layer develop an internal stress, larger than that of the adhesive bonds between the metal and the respective linings as was seen in the micrographs [4]. An analogous phenomenon is probably the cause of failure of paints.

\section{CONCLUSIONS}

Based on the result obtained it can be concluded that dolomite lining offers the best corrosion protection, however in its absence $\mathrm{MgCO}_{3}$ can be applied. It is advocated that the use of plain carbon steel without coating is not recommended but the use of calcite is preferred if dolomite and $\mathrm{MgCO}_{3}$ are not available.

\section{REFERENCES}

1. www.key-to-steel.com/Articles/Art60, accessed on 16/11/2007

2. Amethyst Galleries, Inc, www.galleries.com.minerals/carbonate/dolomite/dolomite, accessed on $21 / 12 / 2007$

3. Amethyst Galleries, Inc, www.galleries.com.minerals/carbonate/calcite/calcite, accessed on $17 / 11 / 2007$

4. Hasson, D., Keysar, S., Semiat, R. and Bramson, D., Corrosion Protection of Mild Steel by a Calcite Layer. Advance ACS Abstracts 1997, 36 (8), 2903-2909

5. McClanahan, M.A. and Mancy, K.H., Effect of $\mathrm{pH}$ on Quality of $\mathrm{CaCO}_{3}$ Deposited from Moderately Hard Water. J. Am. Water Works Assoc. 1974, pp 49, 66

6. Snoeyink, V.I. and Kuch, A., Principles of Metallic Corrosion in Water Distribution Systems, Internal Corrosion of Water Distribution Systems, AWWA Research Foundation and DVGW, Denver, CO, USA, 1985

7. Legrand, A. and Leroy, Y., Prevention of Corrosion and Scaling in Water Supply Systems, Ellis Horwood Series in Water and Waste Water Technology, New York, 1990, p. 262

8. Feigenbaum, C., Gar-Or, L. and Yahalom, J., Scale Protection Criteria in Natural Water', Corrosion 1978, 34(4), p.133

9. Umoru,L.E.; Ige, O.O. Effects of Tin on Al-Zn-Mg Alloy as Sacrificial Anode in Seawater. JMMCE 2007, 7(2), 105-113 